\title{
COR TRILOCULARE BIATRIATUM: FINDINGS AT THORACOTOMY
}

BY

\author{
C. E. DREW, P. R. FLEMING, AND A. M. JOHNSON \\ From Westminster Hospital
}

Since the description by Holmes in 1823 of a case of cor triloculare biatriatum, nearly 100 cases have been recorded. Our case seemed worth publication on account of the associated anomalies and of the method used to confirm and amplify the preoperative diagnosis.

\section{Case Report}

D.G., a male infant, had cyanotic attacks from the age of two weeks. His birth weight was $6 \mathrm{lb}$. and on admission to Westminster Hospital at the age of eight months, he was permanently cyanosed, with early finger clubbing. The second and third toes of each foot were webbed. The apex beat was in the fourth left intercostal space in the anterior axillary line, the pulmonary second sound was single and there were no murmurs. The blood pressure was $70 / 45 \mathrm{~mm}$. Chest X-ray showed enlargement of the heart to the left, a narrow vascular pedicle in the postero-anterior view, and moderate pulmonary congestion.

Angiocardiography (Fig. 1) showed the right pulmonary artery and the aorta filling early and simultaneously and no sign of a left pulmonary artery.' An abnormal pulmonary vein on the right appeared to drain into the superior vena cava or azygos vein.

A provisional diagnosis of Fallot's tetralogy with atresia of the left pulmonary artery was made and thoracotomy was decided upon with a view to a systemic-pulmonary anastomosis if this were found to be feasible.

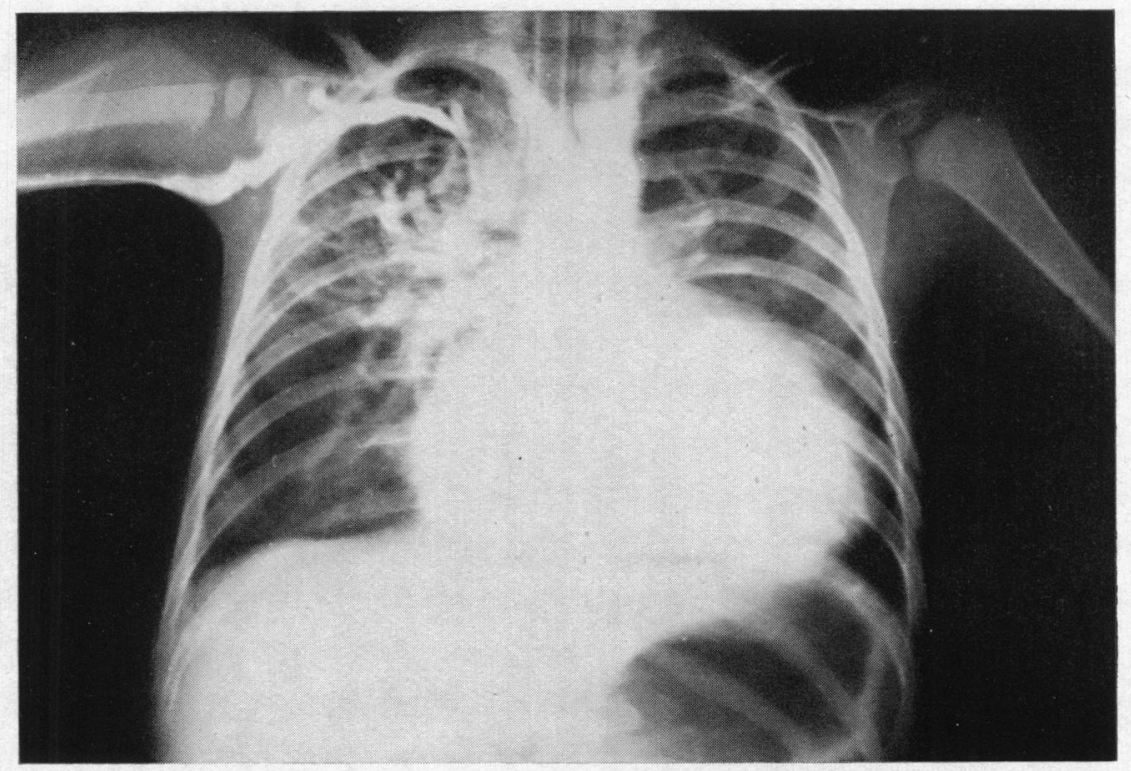

FIG. 1.-Antero-posterior angiocardiogram at $2 \frac{1}{2}$ sec., showing simultaneous filling of the aorta and the right pulmonary artery. 
This was carried out using hypothermia. A trans-sternal incision was made, opening into both pleural cavities. The great vessels were transposed, the aorta arising anteriorly and to the right of a small pulmonary artery which ran to the left lung. No right branch could be found, but a large artery passed from the ascending aorta to the right lung, with the usual divisions of a right pulmonary artery. A vein from the right upper lobe drained into the superior vena cava, but otherwise the pulmonary veins appeared normal.

Blood oxygen saturations in the aorta $(55 \%)$ and the left pulmonary artery $(59 \%)$ were estimated using a Brinkman hæmoreflector and pressures in the left pulmonary artery $(22 / 5 \mathrm{~mm}$. $\mathrm{Hg}$ ) and infundibulum $(65 / 5 \mathrm{~mm}$.) were measured in quick succession, with a Sanborn electromanometer. Pulmonary valvular stenosis was diagnosed and pulmonary valvotomy was performed. The oxygen saturations in the aorta and the left pulmonary artery were now 81 per cent and 80 per cent respectively, but the pulmonary artery and infundibular pressures were unchanged. The possibility of detaching the right pulmonary artery from the aorta and anastomosing it with the left was considered but the similarity of the oxygen saturations in the aorta and left pulmonary artery suggested a single ventricle. This was confirmed by the pressures in "right" and "left" ventricles which were both $48 / 0 \mathrm{~mm}$. $\mathrm{Hg}$, the form of the two curves being identical. No further operative procedure was possible and the chest was closed. The child died three hours later.

\section{Autopsy}

Autopsy (Fig. 2). The venæ cavæ were normal apart from the anomalous vein from the right upper lobe. There was a hypertrophied common ventricle with no trace of a septum. The abnormal arrangement of the great vessels found at operation was confirmed; there was no ductus arteriosus. The pulmonary valve was stenosed, the cusps being represented by two fleshy papillæ, the commissures between which had been split. The left atrium showed hypertrophy $(3 \mathrm{~mm}$.) with thickened endocardium; the inter-atrial septum was intact. The pulmonary veins were grossly hypertrophied. The mitral orifice was minute, with no cusps.

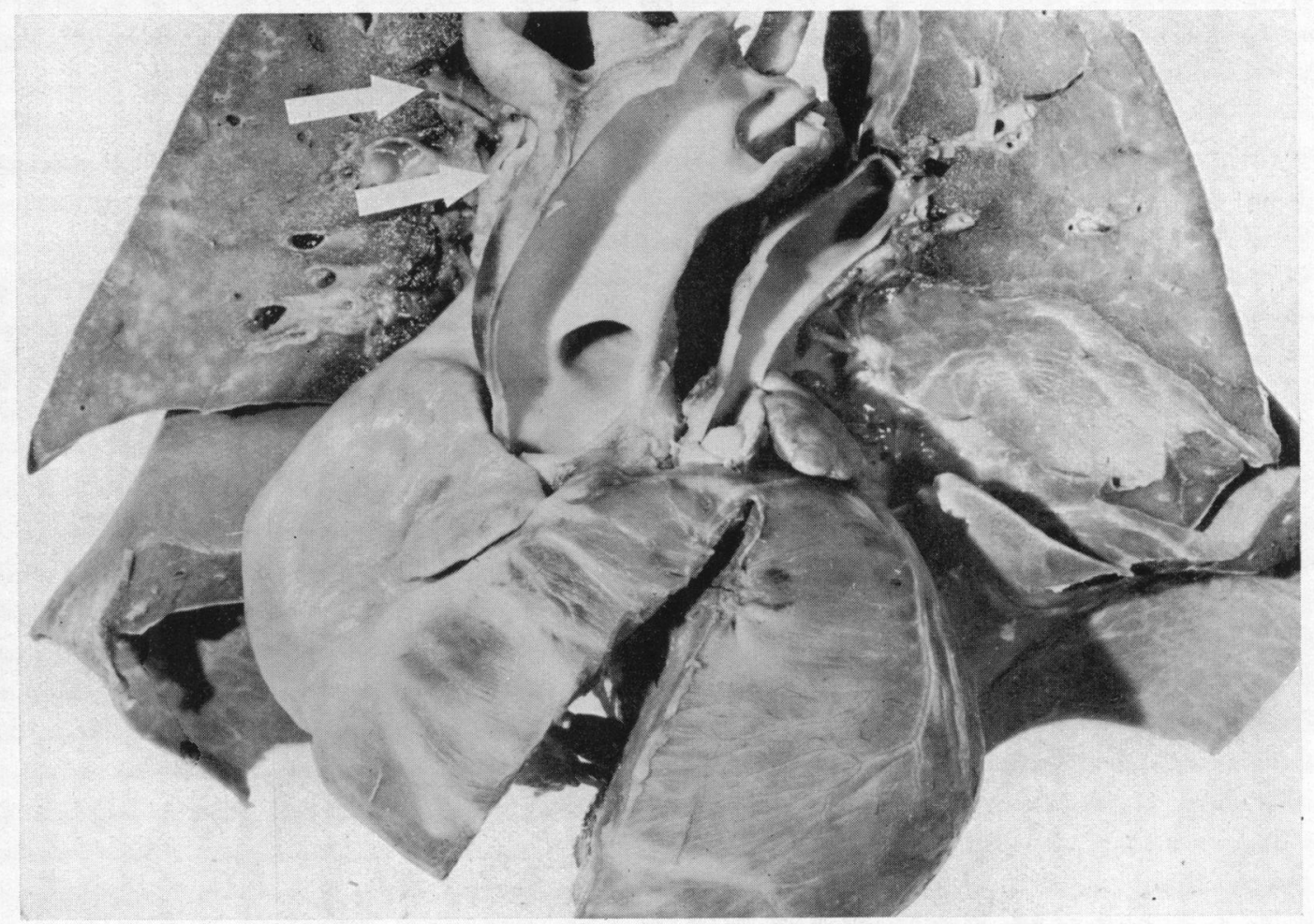

FIG. 2.-Anterior aspect of the autopsy specimen, showing the orifice of the large branch of the aorta passing to the right lung; the left pulmonary artery with valvular stenosis; the anomalous vein (upper arrow) from the right upper lobe draining into the superior vena cava (lower arrow). 
Histological examination of the left atrium showed, in addition to muscular hypertrophy, gross endocardial thickening, the deeper part of which was almost wholly elastic, with a layer of muscle tissue running through it, resembling the appearances seen in fibroelastosis.

\section{Discussion}

The syndrome of single ventricle with pulmonary stenosis has recently been reviewed by Campbell et al. (1953) and only the features in which our case differed from the patterns they described will be discussed.

The most remarkable feature is that life was maintained at all in the presence of such severe mitral stenosis with an intact inter-atrial septum. It would seem that the pulmonary stenosis greatly reduced the blood supply to the left lung and that a large proportion of the total pulmonary venous drainage was carried by the anomalous vein from the right upper lobe. The increase in left pulmonary blood flow resulting from the valvotomy could have contributed to the child's death by precipitating pulmonary œdema.

Nadas et al. (1953) described three cases of Fallot's tetralogy with atresia of the left pulmonary artery. The angiocardiogram suggested this state of affairs in our case and the possibility of performing systemic-pulmonary anastomosis with a branch of the right pulmonary artery was considered, to avoid clamping its main trunk. There was, in fact, no trace of a right pulmonary artery, the right lung being supplied by the large vessel from the ascending aorta.

This method of diagnosis by means of pressure measurements and estimations of oxygen saturations after transverse thoracotomy has not been widely reported. In those cases in which certain preoperative diagnosis is not possible, its use seems worth while as the combined anatomical and physiological study may provide the additional information needed for exact diagnosis. This case illustrates the importance of recording pressures from all the cardiac chambers as unsuspected lesions may otherwise be missed.

\section{Summary}

A description is given of a fatal case of cor triloculare biatriatum in which the following associated anomalies occurred: (1) pulmonary valvular stenosis; (2) absence of the right pulmonary artery, the right lung being supplied by a large branch of the ascending aorta; (3) congenital mitral stenosis, with intact inter-atrial septum and endocardial fibroelastosis of the left atrium; and (4) anomalous right pulmonary venous drainage.

These anomalies are discussed and an account is given of the diagnostic use of pressure measurements and estimations of oxygen saturation at operation. A technically successful pulmonary valvotomy may have contributed to the fatal issue.

We wish to thank Dr. A. A. Cunningham of Kingston Hospital who referred the case, Dr. C. J. Gavey for his advice and encouragement in the preparation of this paper, Dr. A. D. Morgan for the autopsy report and Dr. Peter Hansell for the photographs

\section{References}

Campbell, M., Reynolds, G., and Trounce, J. R. (1953) Guy's Hosp. Rep., $102,99$.

Holmes, W. F. (1824). Trans. Edinb. Med. Chir. Soc., 1, 252.

Nadas, A. S., Rosenbaum, H. D., Wittenborg, M. H., and Rudolph, A. M. (1953). Circulation, 8, 328. 